\title{
Analyzing the structural properties of Fire Clay bricks after adding cigarette filters
}

\author{
Karim Galal Abdullatif, Marianne Nabil Guirguis, Rania Rushdy Moussa \\ Architectural department, Faculty of Engineering \\ The British University in Egypt (BUE) \\ El-Sherouk City, Cairo 11837 \\ EGYPT
}

\begin{abstract}
Cigarette filters are one of the most littered objects in the world that damage the environment. Incorporation in construction bricks offers the prospect of limiting damage and solves the recyclability problem for a typical non-biodegradable waste. This paper aims to explore that prospect, by adding cigarette filters in the production of two samples of fired clay bricks with the cigarette filters comprising $5 \%$ and $10 \%$ of the volume. The mixing and molding processes were done manually which had an effect on the bricks when tested, The results of testing were corresponding with those of previous studies (outside Egypt), however, only one sample of 5\% Cigarette butts volume bricks complied with the Egyptian standards for bricks used in non-load bearing uses. The industrial production of these bricks is highly recommended as it will surpass the required Egyptian standards, save a significant amount of natural resources and eliminate cigarette waste.
\end{abstract}

Key-Words: - Waste Management; Cigarette filters recycling; fire clay bricks; Cigarette butts; sustainable building materials; cigarettes in bricks.

Received: May 1, 2020. Revised: October 2, 2020. Accepted: October 5, 2020.

Published: October 6, 2020.

\section{Introduction}

In the last decade, Living sustainable life and creating sustainable projects has been the main concern of researchers and policy makers. In the last years, the researches presented new ideas addressing sustainable approach such as [1, 2, 3, 4, 5, 6 and 7]. And Some relevant studies can be found in $[8,9$ and 10] This research addressed different sustainable approach by focusing on creating sustainable building material by recycling waste materials and reuse it in the construction industry.

Waste accumulation has become one of the daily problems facing the developing countries citizens. This problem has become a threat to a serious environmental disaster and a good atmosphere for increasing the epidemics as the governments continues to fail to deal with that problem [11].

The presented research studding the effect of integrating cigarette filters with fire-clay bricks on its structural properties.

\section{Cigarette Filters}

Cigarette filters is one of the cigarette components along with the cigarette paper, capsules and adhesives. It was used in the early of 1950's and it does not reduce the negative effect of cigarettes on human on health. Paper, cellulose acetate fibers and activated charcoal are used to made cigarette filters. Cigarette filters compose one of the major littered forms of waste in the world; the number of cigarettes produced each year is in the trillions, consequently, creating millions of waste tonnage [12].

\subsection{Cigarette filters in Egypt}

According to the Tobacco Atlas, in Egypt the butts and packs in trash are estimated to weigh 42304 tonnes annually, roughly equivalent to the weight of 8461 African elephants. In 2016, about 90 billion cigarettes where produced in Egypt [13], which is a 
staggering number that is on the rise, moreover, as smokers complete their unhealthy habit, these cigarette filters are then disposed of either by being littered which is the most common outcome or by allocating proper means of waste disposal. It is difficult to mechanize the recycling of cigarette waste as it is very difficult to ensure the separation and breaking down of the chemicals trapped within it.

\subsection{The negative effect of accumulating Cigarette filters on the Environment}

Cigarette filters are driven by rainwater into sewages and follow the regular flow of sewage water consequently ending up in the ocean subjecting the marine environment into direct contact with the negative chemicals, risking the integrity of freshwaters and the aquatic environments [14]. Generally, cigarette filters end up in direct contact with nature whether it's with organisms of various types or marine environments [15]. During the annual coastal clean-up day in California, cigarette filters were the most consistent and present form of waste over the range of 15 years [16]. This endangers many species that use the beach for multiple reasons as it is considered a habitat to them performing natural behaviour such as breeding, laying eggs, absorbing sun light etc. These species experience critical damage in nutrition and consequently fatality, emphasizing that cigarette filters are not a hazard exclusive to humans; however, it is affecting other organisms [17].

Aluminium, lead, selenium, nickel and zinc are among the metals trapped in cigarette filters result in severe damaging to the surrounding environment when leached [15 and 18]. When these metals react with other chemicals present in filters such as polycyclic aromatic hydrocarbons, aromatic amines, formaldehyde, benzene and various other toxic chemicals result in over 60 compound chemicals that are considered carcinogenic [15].

Cellulose acetate cigarette filters have a very low biodegradability releasing a large number of toxic chemicals during their deterioration [14]. As cellulose acetate is exposed it degrades at various rates according to the conditions in which they are present, from one to two months under anaerobic conditions, six to nine months if present in soil, and colossally up to a year, even longer in water [19]. The regular treatment of waste in terms of collecting the garbage and sending it to landfills taking it away from the beaches and hence marine life would still not solve the issue, as the incineration of the filters would only damage the environment furthermore by releasing all these chemicals into the atmosphere. The incorporation of waste in construction bricks has been the focus of multiple researches recently, it is considered to be a formidable solution to the levels of pollution currently present [20]. The effect such incorporations have on the mechanical properties produces lightweight bricks with various characteristics that could be utilized.

Clay bricks proved their criticalness and durability by remaining till the modern day heavily used regardless of the various adaptations made in regards to their quality of manufacturing and properties [20]. The overall basic role these bricks play could be viewed as one of the reasons of their success [21]. The large availability of the raw material, clay, along with its time prevailing strength against weathering and deterioration are amongst the reasons of its solidified role within the industry, it is critical to uncover all the required information about the properties of clay bricks and maintain the distinct manufacturing steps in order to produce a top-quality clay brick [21].

\section{Methodology}

This flowchart clearly demonstrates the sequence adopted for this brick production procedure as

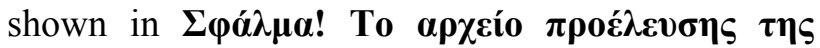

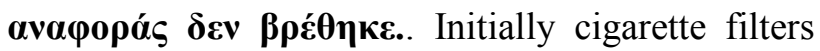
are collected and this particular step will need a certain protocol upon industrialization of this brick. Then normal steps take place with the incorporation of the cigarette filters within the mixture. 


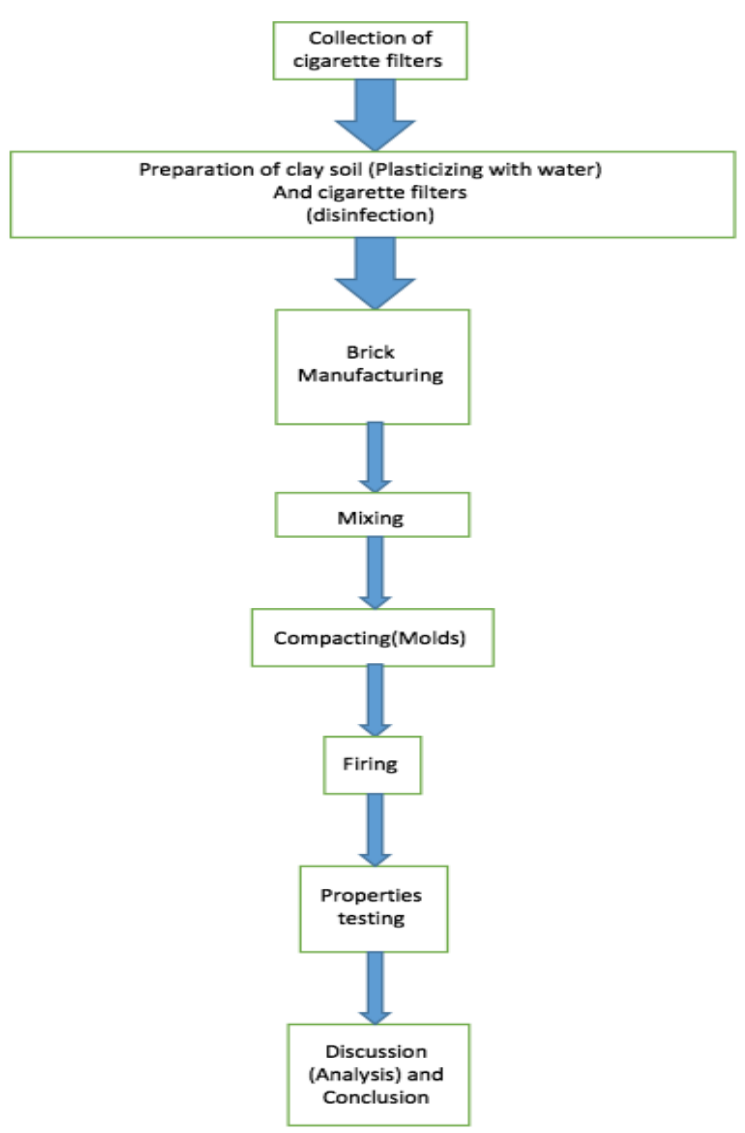

Fig.1. Methodology Chart (Sequence of production procedure) Developed by author

\subsection{Collection \& preparation of filters}

A neighboring coffee-shop having smoking-oriented customers was asked to provide the used cigarette filters instead of disposing them in the garbage. The filters were then collected and soaked in cold water to ease the removal of the plug wrap paper and the tipping paper while cleaning it from any un-smoked tobacco and wrapping paper leaving only the filter itself. Filters were then put into the oven at a 100 degrees Celsius for 24 hours to thoroughly be disinfected. Upon removal from the oven they were then sealed in plastic bags as shown in fFig. 1.

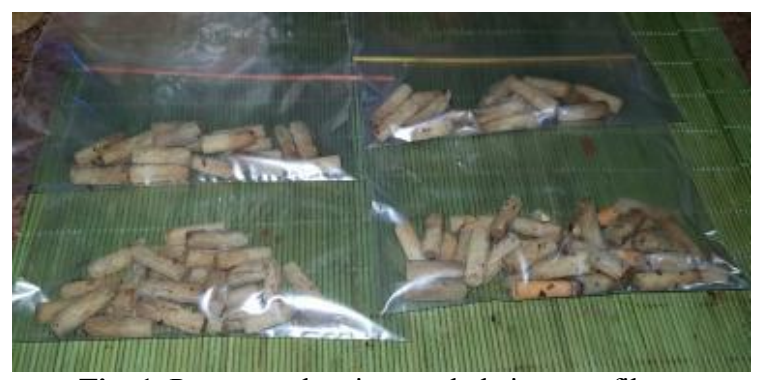

Fig. 1. Post-oven heating, sealed cigarette filters

\subsection{Soil Preparation}

The soil required for the sampling was collected from one of the brick manufacturing factories located at Al-Tibin district on the industrial outskirts of the city of Helwan. According to the workers of the factory the soil had (1:3) sand to clay ratio, and they instructed that the dry soil is to be fermented by adding a small amount of water for 2 days in order that the soil will be ready for use as shown in Fig. 2.

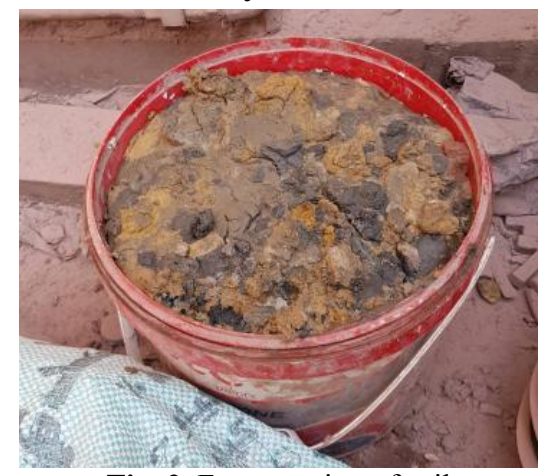

Fig. 2. Fermentation of soil

\subsection{Mixing}

Mixing began using an industrial gun-drilling machine. Its drill was altered at the blacksmith by adding a tilted edge like a curve with a cross above it. These mixing tool enhance the efficiency of the mixing process, allowing the entire amount of mud to be mixed thoroughly and equally. Water was added to increase the plasticity of the clay providing more workability as shown in Fig. 3, the cigarette filters were added on two separate times during the mixing process. The first time was during mixing the first sample was occurring with a concentration of cigarette filters that amounted to $5 \%$ of the total volume of the samples. The second time was during mixing the first sample was occurring with a concentration of cigarette filters that amounted to $10 \%$ of the total volume of the samples.

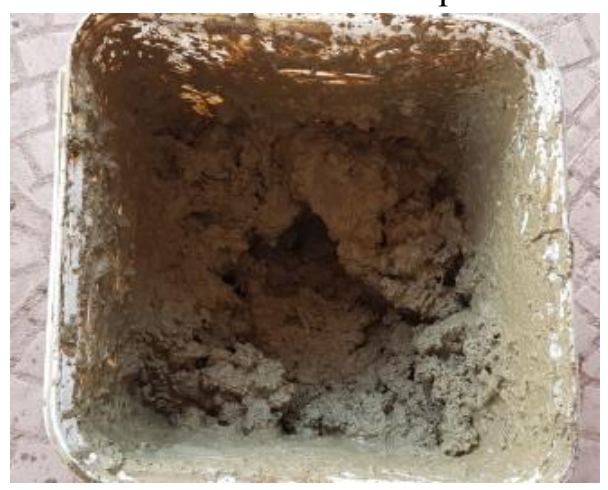


Fig. 3. Mixing process

\subsection{Moulding}

Moulds used were wooden with the following size $20 \mathrm{~cm} \times 10 \mathrm{~cm} \times 6 \mathrm{~cm}$ (length $\times$ width $\times$ height) respectively as shown in Fig. 4. Compaction is then undergone using a vibration sander by steadily moving it along the exterior perimeter of the moulds causing consistent vibrations, thus compaction occurs and allows for air bubbles to appear as it eliminated air gaps within the mould.

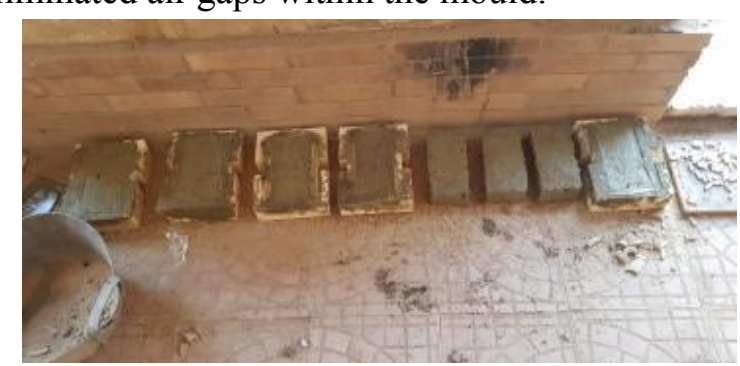

Fig. 4. Casted Moulds

\subsection{Drying}

The bricks are left to dry in the sun for three days as

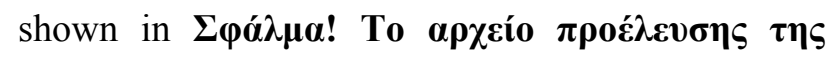

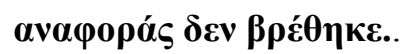

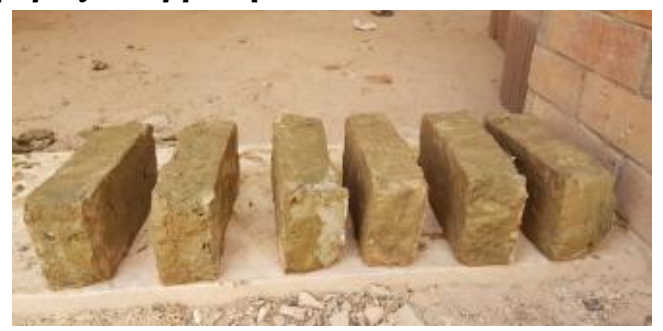

Fig. 5. Moulds removed, bricks left to air-dry

\subsection{Firing}

A kiln was used to undergo the firing stage as shown in Fig. 6. Bricks were fired at a temperature of 950 degrees Celsius for 24 hours. Upon completion of firing they were left to cool for a day.

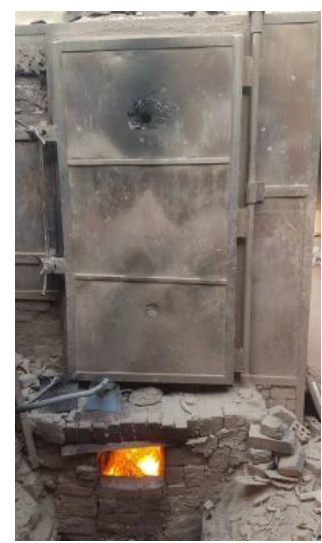

Fig. 6. Oven-kiln firing the bricks

The bricks emerged with the desired red surface colour indicating that they were fired thoroughly. However, during the testing stage a more technical perspective suggested that the bricks may have been over burned in the kiln. It is apparent through viewing figures that there is a stark visual difference between samples having 5\% Cigarette butts'(CB) volume as shown in Fig. 4. Fig. 7 and samples having $10 \%$ Cigarette butts' volume as shown in Fig. 4Fig. 8 and the difference is the amount of surface cracks in the bricks.

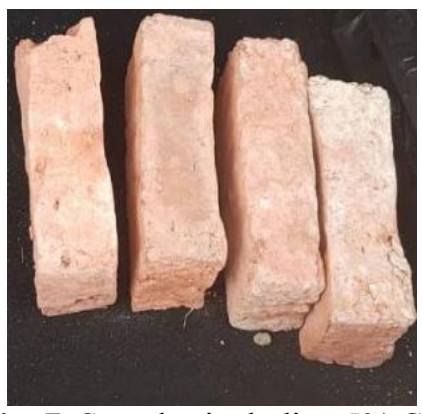

Fig. 7. Samples including 5\% CB

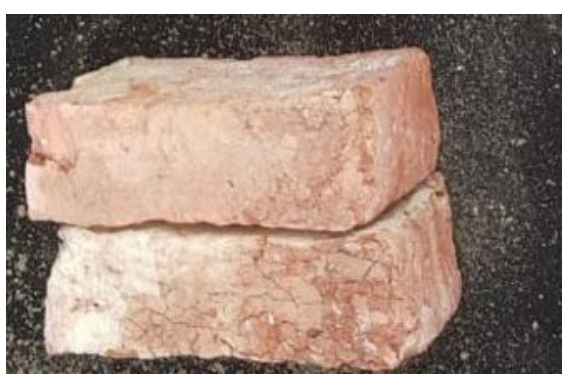

Fig. 8. Samples including $10 \% \mathrm{CB}$

\subsection{Testing Results}

Testing the properties of the fired clay bricks was done at the Consulting Engineering Bureau \& Laboratories (CEL) labs in accordance to the tests requirements by the international and Egyptian 
standards codes. The tests covered the dry density, water absorption rate and the compressive strength as shown below. Knowing that the dimensions of the specimen are as presented in $\Sigma \varphi \alpha \dot{\lambda} \mu \alpha$ ! To

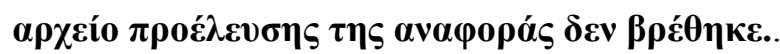

Table 1. Dimensions of bricks post firing

\begin{tabular}{|c|c|c|c|c|c|c|c|}
\hline \multirow{2}{*}{$\begin{array}{l}\text { Sa } \\
\text { mpl } \\
\text { e } \\
\text { No. }\end{array}$} & \multirow{2}{*}{$\begin{array}{l}\text { Mixtu } \\
\text { re } \\
(\mathrm{CB}) \\
\text { by } \\
\text { Volu } \\
\text { me } \\
(\%) \\
\end{array}$} & \multicolumn{3}{|c|}{ Dimension in cm } & \multirow{2}{*}{$\begin{array}{l}\text { Area } \\
/ \mathrm{cm}^{2}\end{array}$} & \multirow{2}{*}{$\begin{array}{l}\text { Volu } \\
\text { me } \\
/ \mathrm{cm}^{3}\end{array}$} & \multirow{2}{*}{$\begin{array}{l}\text { Weig } \\
\text { ht/kg }\end{array}$} \\
\hline & & $\mathbf{L}$ & $\mathbf{W}$ & $\mathbf{H}$ & & & \\
\hline 1 & 5 & 17.5 & 8.30 & $\begin{array}{l}5.5 \\
0\end{array}$ & 145 & 799 & 1.30 \\
\hline 2 & 5 & 17.6 & 9.00 & $\begin{array}{l}5.2 \\
0\end{array}$ & $\begin{array}{l}158 . \\
4\end{array}$ & 824 & 1.28 \\
\hline 3 & 5 & 18.5 & 9.20 & $\begin{array}{l}5.1 \\
0\end{array}$ & 170 & 868 & 1.35 \\
\hline 4 & 5 & 18.0 & 8.00 & $\begin{array}{l}5.5 \\
0\end{array}$ & 144 & 792 & 1.31 \\
\hline 5 & 10 & 17.7 & 8.50 & $\begin{array}{l}5.1 \\
0\end{array}$ & 151 & 768 & 1.24 \\
\hline 6 & 10 & 18.0 & 9.00 & $\begin{array}{l}5.0 \\
0\end{array}$ & 162 & 810 & 1.28 \\
\hline
\end{tabular}

\subsubsection{Dry Density}

The dry density is derived by measuring the dry weight of each sample brick and calculating its dry density by dividing its weight by the corresponding volume. As the control brick sample was not manufactured, an assumption was made placing the bulk dry density of fired clay bricks containing $0 \%$ of cigarette butts in volume at $2000 \mathrm{~kg} / \mathrm{m} 3$, while referring to previous researches tackling the same topic [19]. It is clear to note that the bulk density of the samples decreases with an increase in cigarette butts content, which is an inversely proportional relationship as presented in tTable 2 .

Table 2. Dry density

\begin{tabular}{lllll}
\hline $\begin{array}{l}\text { Sample } \\
\text { No. }\end{array}$ & $\begin{array}{l}\text { Mixture } \\
(\mathbf{C B}) \quad \text { by } \\
\text { Volume } \\
(\%)\end{array}$ & $\begin{array}{l}\text { Sample } \\
\text { Volume } \\
\left(\mathrm{m}^{3}\right)\end{array}$ & $\begin{array}{l}\text { Weight } \\
(\mathrm{kg})\end{array}$ & $\begin{array}{l}\text { Density } \\
(\mathrm{kg} / \\
\left.\mathrm{m}^{3}\right)\end{array}$ \\
\hline $\mathbf{1}$ & 5 & 0.000799 & 1.30 & 1627
\end{tabular}

\begin{tabular}{lcccc}
$\mathbf{2}$ & 5 & 0.000824 & 1.28 & 1553 \\
$\mathbf{3}$ & 5 & 0.000868 & 1.35 & 1555 \\
$\mathbf{4}$ & 5 & 0.000792 & 1.31 & 1654 \\
$\mathbf{5}$ & 10 & 0.000768 & 1.24 & 1614 \\
$\mathbf{6}$ & 10 & 0.000810 & 1.28 & 1580 \\
\hline
\end{tabular}

\subsubsection{Water Absorption}

Sample bricks dried in an oven for 3 hours at 250 degrees Celsius using the pressing machine presented in fig. 10, then removed and submerged in room temperature water for 24 hours to measure the amount of water that is absorbed. Upon removing from the oven the brick was left to cool down to the room temperature. Then it was weighed in order to record the dry weight of the brick. Then, the brick was submerged into the room temperature water. After completing the 24-hour submerging period the brick was then dabbed over a cloth in order to remove any excess water on the surface and the brick was weighed again to record the brick's wet weight. Both of the recorded weights are substituted into the following equation to calculate the water absorption: $\left(\frac{W_{W}-W_{D}}{W_{D}}\right) \times 100=$ Water Absorption percentage.

The water absorption recorded for the specimen equals $16 \%$.

\subsubsection{Compressive Strength}

Measuring the compressive strength was achieved by placing the sample bricks in the compressing testing machine that exerted load that is maintained at a specific rate as shown in Fig. 9. Two sheets of plywood were placed beneath and above the brick for even load distribution. The machine started to press consistently until failure occurred to the brick. Upon failure the machine stops pressing and record the breaking load. 


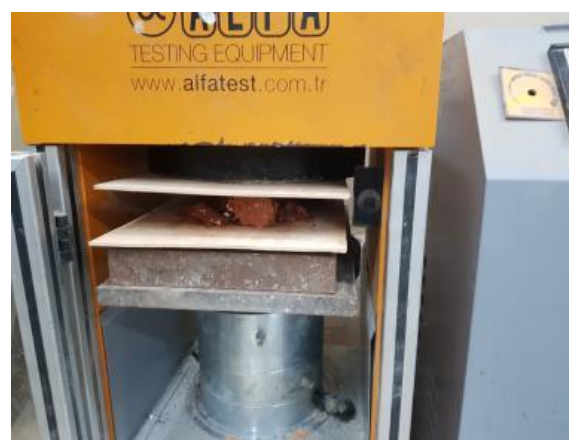

Fig. 9. Pressing machine applying load on the bricks This procedure was done on each brick; the breaking load of each brick was then divided by the area of each brick resulting in the corresponding compressive strength of each brick as presented in tTable 3. As the control brick was not manufactured, a compressive strength of 25 mega Pascal was assumed in reference to previous studies made covering the same point [19]. It is noted that the compressive strength of the bricks decreased as the content of cigarette butts in volume increased presenting an inversely proportional relationship as shown in fFig. 10.

Table 3. Compressive Strength of CB bricks

\begin{tabular}{|c|c|c|c|c|}
\hline $\begin{array}{l}\text { Sampl } \\
\text { e No. }\end{array}$ & $\begin{array}{l}\text { Mixtur } \\
\text { e CB by } \\
\text { Volume } \\
(\%) \\
\end{array}$ & $\begin{array}{l}\text { Compressiv } \\
\text { e } \quad \text { Stress } \\
\left(\mathrm{kgcm}^{2}\right)\end{array}$ & $\begin{array}{l}\text { Breakin } \\
\text { g Load/ } \\
\text { kN }\end{array}$ & $\begin{array}{l}\text { Compressiv } \\
\text { e Strength/ } \\
\text { MPa }\end{array}$ \\
\hline 1 & 5 & 91.6 & 131 & 9.00 \\
\hline 2 & 5 & 78.8 & 122 & 7.70 \\
\hline 3 & 5 & 65.6 & 111 & 6.50 \\
\hline 5 & 10 & 66.3 & 97.8 & 6.50 \\
\hline 6 & 10 & 67.1 & 107 & 6.60 \\
\hline
\end{tabular}

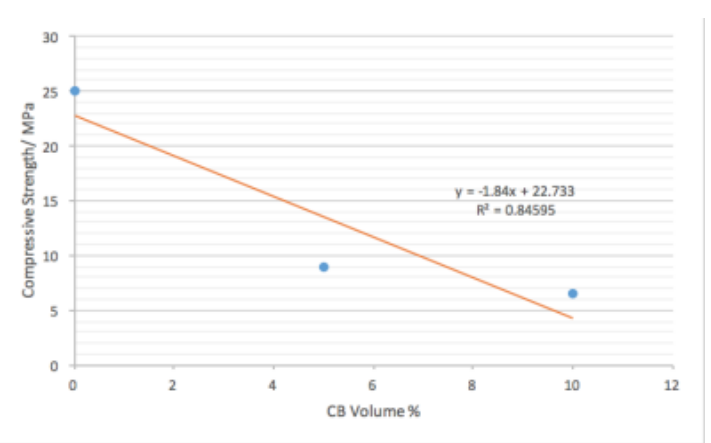

Fig. 10. Compressive Strength graph

\section{Clay Bricks International Standards}

The international and Egyptian standards for masonry units made of clay classify brick types in reference to weathering in 3 different classifications (ES 4763: Building brick masonry units made from clay., 2006) [22]:

a) SW: is for severe weather conditions

b) MW: is for moderate weather conditions

c) NW: neglects weather conditions

These classifications refer to the degree of weather conditions a given brick is subjected to and how it could withstand various levels of weather conditions [23].

\subsection{Compressive Strength}

The following table outlines the compressive strength standards with correspondence to the weather condition classification [22]

Table 4. Egyptian Standards for compressive strength (Classifications)

\begin{tabular}{|c|c|c|}
\hline \multirow[t]{2}{*}{ Classification } & \multicolumn{2}{|c|}{$\begin{array}{l}\text { Minimum Compressive } \\
\text { Strength (Mega Pascal) }\end{array}$} \\
\hline & $\begin{array}{l}\text { Average of five } \\
\text { samples }\end{array}$ & $\begin{array}{l}\text { Individual } \\
\text { sample }\end{array}$ \\
\hline SW(Severe1 Weather) & 20.8 & 17.2 \\
\hline $\begin{array}{l}\text { MW(Moderate } \\
\text { Weather) }\end{array}$ & 17.2 & 15.2 \\
\hline $\begin{array}{l}\text { NW(Neglecting } \\
\text { Weather) }\end{array}$ & 10.3 & 8.6 \\
\hline
\end{tabular}

\subsection{Water Absorption}

The maximum allowed water absorption in which the brick sample is submerged in cold water for 24 hours is $8 \%$ for the SW and $9 \%$ for both the Mw and NW according to the Egyptian standards.

\section{Economic analysis of clay brick with Cigarette filters}

Table 5. Prices \& properties of bricks in Egyptian market (source: market survey by author)

\begin{tabular}{lll}
\hline Type of brick & \multicolumn{2}{c}{ Brick properties } \\
& \multicolumn{2}{c}{} \\
\cline { 2 - 3 } & $\begin{array}{l}\text { Cost of 1000 brick } \\
\text { in September 2020 }\end{array}$ & Dimensions \\
\hline Cement bricks & 630 EGP & $25 \times 12.5 \times 6$ \\
Hollow block & 3,729 EGP & $40 \times 20 \times 12$ \\
Hollow block & 4,746 EGP & $40 \times 20 \times 20$
\end{tabular}




\begin{tabular}{lll} 
Clay brick & 495 EGP & $25 \times 12 \times 6.5$ \\
Clay brick & 918 EGP & $25 \times 12 \times 13$ \\
Sand brick & 839 EGP & $25 \times 12 \times 6$ \\
\hline
\end{tabular}

According to the Egyptian market, the cost of every 1,000 clay brick ranged between 490 to 500 EGP as presented in table 5. The presented research intended to add 5 and $10 \%$ of cigarette butts' to the clay brick. The replacement of clay with cigarette filter will decrease the cost of clay bricks with 25 to 50 EGP for every 1,000 clay brick.

This calculation does not consider the transportation cost nor the filtration cost. Transporting cigarette filters from the dumping area to the industry zoon (clay brick factory) should be calculated. Moreover, the garbage filtration in which it separate the cigarette filters from the rest of the garbage bags also should be calculated. In this research the transportation and filtration process were conducted by the researchers.

According to the calculation presented in table 5 and to the research outcomes, using cigarette filter in clay bricks will not affect the cost of clay bricks and it will not affect economically the construction industry and it will not reduce the building cost but it will partially reduce the negative effect of nonrecycled waste such as cigarette filter in the environment.

\section{Conclusion}

As the world's population numbers increase gradually over the upcoming decades, with it consequently Egypt's population, the number of cigarettes being smoked and littered will increase as well [24]. With more than $20 \%$ of its population smoking, Egypt has a significant task to face in terms of eliminating littering and adjusting its garbage collection and disposal systems however assuming an ideal scenario where $100 \%$ littered garbage is allocated in landfills [25]. The issue cigarette filters impose would still be ongoing as its reaction with the environment would lead to hazardous implications. The results of the compressive strength all it be that it fell short below the required Egyptian standard, it still showed promising numbers. The shortcomings of the results positively outlined the issues that were present in the manufacturing steps and set a minimum benchmark which did not fall far behind the required results while complying with international standards as well as the results of previous studies. The results outlined how the mechanical properties of the brick are inversely proportional to the amount of cigarette filters added into the mixture and given a specific low amount of cigarette filters would maintain the mechanical properties of the brick within the required Egyptian standards. Considering that there is 5.7 trillion cigarettes produced each year, a statistic compiled in 2013 the amount of waste produced in terms of filters is estimated to be 1.2 million tonnes which consequently derives to a certain conclusion that is only $2.5 \%$ of bricks manufactured world-wide require to have $1 \%$ in weight or ranging around $2.5 \%$ in volume of cigarette filters to completely eliminate cigarette filter waste completely [16]. In this study, bricks having a $5 \%$ of the volume consist of cigarette filters met the minimum non-load bearing requirements for Egyptian standards. The industrialized production of such bricks is highly recommended as it will exceed the Egyptian standards requirements in all classifications.

In addition, the use of $2.5 \%$ of cigarette filters in bricks' volumes would provide even better characteristics and properties to the brick, having volumes that vary from $2.5 \%$ to $10 \%$ of brick volume would provide a wide variety of bricks that qualify for multiple uses according to their properties and requirements is strongly recommended.

\section{Future Directions}

It is recommended in future research to try samples with chopped cigarette filters, this is expected to meet the same aim but provide better numerical results than this attempt relative to standards.

The incorporation of cigarette filters provides a means of recycling an object that is nonbiodegradable and to a significant extent nonrecyclable, hence, the implications these filters impose to the environment will be minimized, and thus, limiting the consumption of finite natural resources in the globe. 


\section{References:}

[1] Kralj, D. and Markič, M. (2008). Building Materials Reuse and Recycle. WSEAS Transactions on Environment and Development, 4 (5); 409-418.

[2] Moussa, R.R., Mahmoud, A.H., and Hatem, T.M. (2020). A digital tool for integrating renewable energy devices within landscape elements: Energy-scape online application. Journal of Cleaner Production, 254; 1-13. Retrieved from: https://doi.org/10.1016/j.jclepro.2019.119932

[3] Solban, M.M. and Moussa, R.R. (2019). Piezoelectric Tiles Is a Sustainable Approach for Designing Interior Spaces and Creating SelfSustain Projects. (November, 28 -30). (BSCairo2019) Simulation for a Sustainable Built Environment, Cairo_ Egypt. IOP Conf. Series: Earth and Environmental Science 397012020 Retrieved from: doi:10.1088/1755$1315 / 397 / 1 / 012020$

[4] Cardoso, R., paiva, A., pinto, J. and lanzinha, J.C. (2019). Structural and Material Characterization of a Haussmann Building Complex at La Madeleine, Paris. The First Step Before Sustainable Rehabilitation and Strengthening. WSEAS Transactions on Environment and Development, 15; 14-21.

[5] Moussa, R.R., (2020). Integrating Piezoelectric cells with Children Outdoor Playing areas to Create Clean \& Healthy Environment; Case Study of El-Shams Sporting Club, Cairo_Egypt. WSEAS Transactions on Environment and Development, 16; 471-479. Retrieved from: https://doi.org/10.37394/232015.2020.16.48

[6] Dewidar, K., Guirguis, M.N., Abdelsalam, A.E. (2019).THE MARRIAGE BETWEEN ARCHITECTURE AND SUSTAINABILITY. ALGAE BASED TOWERS A NEW PROPOSAL FOR TOWER DESIGN IN EGYPT. Conference: 7th Annual International Conference on Architecture and Civil Engineering (ACE 2019) 27th - 28th May 2019 Singapore.

DOI: $10.5176 / 2301-$ 394X_ACE19.584
[7] Moussa, R.R. and Dewidar, K.M. (2020). Energy-scape web-based application is an effective tool to overcome the basic knowledge of architects toward renewable energy properties. International Journal of Emerging Technologies in Learning (iJET), 15(10); 42-54. Retrieved https://doi.org/10.3991/ijet.v15i10.13669

[8] Michal Strba, Marcela Karmazinova and Veronika Vaclavikova, The influence of material and geometric parameters on the design of steel mechanical anchors to concrete under tension loading, International Journal of Mechanics, pp. 131-139, Volume 12, 2018.

[9] Moussa, R.R. (2018). The role of energy-scape elements in creating sustainable economic project in Egyptian parks. Ain Shams Engineering Journal, 9(4); 3045-3053.

[10] Parinita Baruah, Sudip Basack, Ghritartha Goswami, Compressive Strength of Interlocking Concrete Pavement Block influenced by Admixtures, International Journal of Mechanics, pp. 58-61, Volume 14, 2020.

[11] Guirguis, M.N. and Moussa, R.R. (2019). Investigation on utilizing garbage as a resource for a sustainable neighbourhood; Case study of a neighbourhood in New Cairo, (November, 28 30). (BSCairo2019) Simulation for a Sustainable Built Environment, Cairo_ Egypt. IOP Conf. Series: Earth and Environmental Science 397012018. Retrieved 15, December 2019, from: doi:10.1088/1755-1315/397/1/012018

[12] Kurmus, H. and Mohajerani, A. (2020) 'Recycling of cigarette butts in fired clay bricks: A new laboratory investigation', Materials. MDPI AG, 13(3). doi: 10.3390/ma13030790.

[13] The Tobacco Atlas (2020) American Cancer Society, Inc. and Vital Strategies. Available at: https://tobaccoatlas.org/country/egypt/.

[14]Poppendieck, D. G., Khurshid, S. S. and Emmerich, S. J. (2016) Measuring Airborne Emissions from Cigarette Butts: Literature Review and Experimental Plan. U.S. doi: 10.6028/NIST.IR.8147.

[15] Abdul Kadir, A. and Amira Sarani, N. (2015) 'Cigarette Butts Pollution and Environmental Impact - A Review', Applied Mechanics and Materials, 73-774, pp. 106-1110. doi: 10.4028/www.scientific.net/AMM.773774.1106 
[16] Novotny, T. E. et al. (2009) 'Cigarettes butts and the case for an environmental policy on hazardous cigarette waste', International Journal of Environmental Research and Public Health. Multidisciplinary Digital Publishing Institute (MDPI), 6(5), pp. 1691-1705. doi: 10.3390/ijerph6051691.

[17] Salleh, I. Bin (2012) Study on properties of clay brick and cigarette butt brick under different heating rates. University Tun Hussein Onn Malasyia, Faculty of Civil and Environmental Engineering.

[18] Moussa, R.R. (2019). The Reasons For Not Implementing Green Pyramid Rating System In Egyptian Buildings. Ain Shams Engineering Journal, 10(4); 917-927.

[19] Mohajerani, A., Kadir, A. A. and Larobina, L. (2016) 'A practical proposal for solving the world's cigarette butt problem: Recycling in fired clay bricks', Waste Management. Elsevier Ltd, 52, pp. 228-244. doi: 10.1016/j.wasman.2016.03.012

[20] Kadir, A. A. and Mohajerani, A. (2011) 'Bricks: an excellent building material for recycling wastes-a review', in Proceedings of the IASTED International Conference. Calgary, $\mathrm{AB}$, Canada: Environmental Management and Engineering. doi: 10.2316/P.2011.736-029.

[21] Fernandes, F. M., Lourenço, P. B. and Castro, F. (2010) 'Ancient Clay Bricks: Manufacture and Properties', in Materials, Technologies and Practice in Historic Heritage Structures. Springer Netherlands, pp. 29-48. doi: 10.1007/978-90-481-2684-2_3.

[22]ES 4763: Building brick masonry units made from clay. (2006). Cairo.

[23]ASTM C 90/2003 Standard specification for loadbearing concrete masonry units. ASTMInternational,USA.https://www.astm.org/ DATABASE.CART/HISTORICAL/C90-03.htm

[24]Fouda, S. et al. (2018) 'Tobacco smoking in Egypt: a scoping literature review of its epidemiology and control measures', EMHJ, 24(2). doi: 10.26719/2018.24.2.198.

[25] Loffredo, C. A. et al. (2015) 'Estimates of the Prevalence of Tobacco Smoking in Egypt', Open Journal of Epidemiology. Scientific Research Publishing, Inc, 05(02), pp. 129-135. doi: 10.4236/ojepi.2015.52017.

\section{Creative Commons Attribution License 4.0 (Attribution 4.0 International, CC BY 4.0)}

This article is published under the terms of the Creative Commons Attribution License 4.0

https://creativecommons.org/licenses/by/4.0/deed.en US 